\title{
Is once daily multimatrix mesalazine therapy effective regardless of the dose in patients with mild to moderate ulcerative colitis?
}

\author{
Seong Ran Jeon \\ Digestive Disease Center, Institute for Digestive Research, Soonchunhyang University College of Medicine, Seoul, Korea
}

Article: Comparison of efficacy of once daily multimatrix mesalazine $2.4 \mathrm{~g} /$ day and $4.8 \mathrm{~g} /$ day with other 5-aminosalicylic acid preparation in active ulcerative colitis: a randomized, doubleblind study (Intest Res 2018;16:255-266)

Mesalazine (5-aminosalicylic acid, 5-ASA) is the first-line therapy for patients with mild to moderate UC. ${ }^{1}$ Mesalazine has been reported to be effective, safe, and well-tolerated in patients with UC. Although the precise mechanism of 5-ASA is not clear, investigations have demonstrated its anti-inflammatory and immunosuppressive properties, which suggests that the mechanism is multifactorial. ${ }^{2}$ According to delivery system, mesalazine is divided into different types: ${ }^{1}(1) \mathrm{pH}-$ release mesalazine $\left(\right.$ Asacol $\left.^{\circledR}\right)$, which uses a gastro-resistant coating that dissolves at a $\mathrm{pH} \geq 7$; (2) controlled-release mesalazine (Pentasa ${ }^{\circledR}$ ) consists of microspheres containing mesalazine enclosed within an ethylcellulose semi-permeable membrane, which allows the release of 5-ASA in a timesensitive manner; and (3) multi-matrix system (MMX) mesalazine (Mezavant ${ }^{\circledR}$ and Lialda ${ }^{\circledR}$ ) utilizes a pH-dependent film ( $\mathrm{pH} 7)$ to resist gastric breakdown and to deliver 5-ASA throughout the colon. ${ }^{2}$

The effectiveness of MMX mesalazine in inducing remission has been reported by 2 large phase III studies. ${ }^{3,4}$ In the first study ( $\mathrm{n}=280)$, clinical remission (CR) and endoscopic remission (ER) rates were higher with both MMX mesalazine $2.4 \mathrm{~g} /$ day ( $1.2 \mathrm{~g}$ twice daily; $34.1 \%, P<0.001)$ and $4.8 \mathrm{~g}$ (once daily; 29.2\%, $P=0.009$ ) than those with placebo (12.9\%)

Received March 5, 2018. Revised March 7, 2018. Accepted March 7, 2018. Correspondence to Seong Ran Jeon, Digestive Disease Center, Institute for Digestive Research, Soonchunhyang University College of Medicine, 59 Daesagwan-ro, Yongsan-gu, Seoul 04401, Korea. Tel: +82-2-709-9202, Fax: +82-2-709-9696, E-mail: 94jsr@hanmail.net after 8 weeks. ${ }^{3}$ The second $(n=343)$ study compared 2 different doses of MMX mesalazine (2.4 and $4.8 \mathrm{~g}$ once daily), pH-release mesalazine $2.4 \mathrm{~g} /$ day (800 mg thrice daily), and placebo. ${ }^{4}$ After 8 weeks, the CR and ER rates were higher in patients who received either MMX mesalazine $2.4 \mathrm{~g} /$ day $(40.5 \%, P=0.01)$ or $4.8 \mathrm{~g} / \mathrm{day}(41.2 \%, P=0.007)$. However, $\mathrm{pH}-$ release mesalazine $2.4 \mathrm{~g}$ /day was not significantly (32.6\%, $P=0.124)$ better than the placebo (22.1\%) in terms of CR and ER rates. Generally, MMX mesalazine was well tolerated among the patients in these studies. ${ }^{3,4}$ A subsequent analysis of pooled data from 2 MMX mesalazine phase III studies demonstrated that the administration of 2 doses (2.4 and 4.8 $\mathrm{g}$ /day) of mesalazine was effective in inducing CR and ER in patients with mild to moderate UC. ${ }^{5}$

In the current issue of Intestinal Research, Ogata et al. ${ }^{6}$ investigated the efficacy and safety of 2 doses of MMX mesalazine (2.4 [MMX-2.4 group] and 4.8 g/day [MMX-4.8 group]) compared with controlled-release mesalazine $2.25 \mathrm{~g}$ /day (thrice daily, controlled-2.25 group). Patients were randomly assigned either to MMX-2.4 ( $\mathrm{n}=85)$, MMX-4.8 ( $\mathrm{n}=81)$, or controlled-2.25 group $(\mathrm{n}=85)$ for 8 weeks. The primary endpoint was to demonstrate the non-inferiority of MMX-2.4 g/day to controlled-2.25 g/day and the superiority of MMX-4.8 g/day to controlled-2.25 g/day based on changes in the UC-disease activity index (UC-DAI) score. The secondary endpoints included remission (defined as UC-DAI score $\leq 2$ and rectal bleeding score $=0$ ) and ER (defined as UC-DAI subscore $=0$ ).

๑ Copyright 2018. Korean Association for the Study of Intestinal Diseases. All rights reserved.

This is an Open Access article distributed under the terms of the Creative Commons Attribution Non-Commercial License (http://creativecommons.org/licenses/by-nc/4.0)

which permits unrestricted non-commercial use, distribution, and reproduction in any medium, provided the original work is properly cited. 
In terms of primary endpoint, the difference in the UC-DAI score between the MMX-2.4 and controlled-2.25 groups was 0.3 (two-sided $95 \% \mathrm{CI},-0.5$ to 1.1 ), which did not meet the non-inferiority criteria. However, the difference in the UCDAI score between the MMX-4.8 and controlled-2.25 groups was -1.2 (two-sided $95 \% \mathrm{CI},-2.0$ to -0.5 ) with a significant difference. The difference in UC-DAI score for the MMX4.8 and MMX-2.4 groups was -3.3 (two-sided 95\% CI, -3.9 to -2.8 ) and -1.9 (two-sided 95\% CI, -2.5 to -1.3 ), respectively. The percent of remission (MMX-2.4 vs. MMX-4.8 vs. controlled-2.25, $31.8 \%$ vs. $45.7 \%$ vs. $28.2 \%$, respectively) and ER ( $10.6 \%$ vs. $19.8 \%$ vs. $14.1 \%$, respectively) was similar between the MMX-2.4 and controlled-2.25 groups, while the percent of remission of the MMX-4.8 group was higher than those of the controlled-2.25 group. Adverse events (AEs) exhibited no difference among each group. The study revealed that MMX-4.8 g/day was more effective than MMX-2.4 g/day and controlled-2.25 g/day. Although non-inferiority was not met, considering the secondary endpoint, the authors concluded that the efficacy of MMX-2.4 g/day was comparable to that of controlled-2.25 g/day.

These results of the study by Ogata et al. ${ }^{6}$ were similar to that of a recent meta-analysis. ${ }^{7}$ The meta-analysis demonstrated that $50 \%$ of patients who received 5 -ASA failed to achieve remission compared to $52 \%$ of patients who received 5-ASA comparator (RR, 0.94; 95\% CI, 0.86-1.02). This suggested that there was no difference among the various 5-ASA formulations in terms of efficacy. ${ }^{7}$ Furthermore, there were no significant differences between high and low doses of 5-ASA?

Unlike the study by Ogata et al., ${ }^{6}$ the meta-analysis did not assess the significant difference in efficacy between the two 5-ASA dosing regimens ( $4.8 \mathrm{~g}$ /day vs. $2.4 \mathrm{~g} /$ day), including pH-release and MMX mesalazines. ${ }^{7}$ However, similar to the present study, ${ }^{6}$ subgroup analysis of several studies demonstrated that patients with moderate UC might benefit from the high dose of mesalazine $(4.8 \mathrm{~g} /$ day $){ }^{7-9}$ This indicates that the severity of disease can be a factor that affects the response to 5-ASA treatment. ${ }^{8,9}$ A previous study reported that MMX mesalazine at a dosage of 2.4 or $4.8 \mathrm{~g}$ /day is superior to placebo in the induction of CR and ER in 517 patients with mild to moderate UC. ${ }^{9}$ However, in those patients transferred directly from prior low-dose 5-ASA, MMX mesalazine $4.8 \mathrm{~g} /$ day was superior to placebo, while its efficacy over placebo in patients transferred directly to MMX mesalazine $2.4 \mathrm{~g}$ /day was not significantly different. Ogata et al. ${ }^{6}$ also reported that MMX-4.8 g/day had more beneficial than $2.4 \mathrm{~g}$ /day because more than $80 \%$ patients were directly transferred from prior low-dose 5-ASA. This suggested that the non-responders to low-dose 5-ASA might respond to escalation in the dose of MMX mesalazine. ${ }^{9}$ This treatment strategy has been supported by the findings of another study. The study reported that there was a significant benefit of $\mathrm{pH}$-release mesalazine $4.8 \mathrm{~g}$ /day compared to $2.4 \mathrm{~g} /$ day dosing in patients with difficult-to-treat UC (e.g., patients who needed steroids or more than 2 medications-steroids, immunomodulators, oral 5-ASA, or rectal 5-ASA). ${ }^{10}$

In summary, the current data by Ogata et al. ${ }^{6}$ support that the efficacy of oral MMX-2.4 g/day is comparable to that of controlled- $2.25 \mathrm{~g} /$ day, and MMX-4.8 g/day is more effective than $2.4 \mathrm{~g} /$ day in inducing remission in patients with mild to moderate UC without associated safety concerns. This implies the possibility that sample size and proportion of the prior use of low-dose 5-ASA or patients with moderate UC may affect the result. However, the efficacy of MMX mesalazine was restricted only to induction of remission of UC. Therefore, to ensure the maintenance of long-term remission in Asian patients with UC, further large, prospective, and randomized trials to determine the optimal dose and use of MMX mesalazine are necessary.

\section{FINANCIAL SUPPORT}

The authors received no financial support for the research, authorship, and/or publication of this article.

\section{CONFLICT OF INTEREST}

No potential conflict of interest relevant to this article was reported.

\section{AUTHOR CONTRIBUTION}

Writing and approval of final manuscript: SR Jeon.

\section{REFERENCES}

1. Choi CH, Moon W, Kim YS, et al. Second Korean guidelines for the management of ulcerative colitis. Intest Res 2017;15:7-37.

2. Kedia P, Cohen RD. Once-daily MMX mesalamine for the treatment of mild-to-moderate ulcerative colitis. Ther Clin Risk Manag 2007;3:919-927.

3. Lichtenstein GR, Kamm MA, Boddu P, et al. Effect of once- or twice-daily MMX mesalamine (SPD476) for the induction of remission of mild to moderately active ulcerative colitis. Clin Gastroenterol Hepatol 2007;5:95-102. 
4. Kamm MA, Sandborn WJ, Gassull M, et al. Once-daily, highconcentration MMX mesalamine in active ulcerative colitis. Gastroenterology 2007;132:66-75.

5. Sandborn WJ, Kamm MA, Lichtenstein GR, Lyne A, Butler T, Joseph RE. MMX Multi Matrix System mesalazine for the induction of remission in patients with mild-to-moderate ulcerative colitis: a combined analysis of two randomized, double-blind, placebo-controlled trials. Aliment Pharmacol Ther 2007;26:205215.

6. Ogata H, Yokoyama T, Mizushima S, Hagino A, Hibi T. Comparison of efficacy of once daily multimatrix mesalazine $2.4 \mathrm{~g} /$ day and $4.8 \mathrm{~g} /$ day with other 5-aminosalicylic acid preparation in active ulcerative colitis: a randomized, double-blind study. Intest Res 2018;16:255-266.
7. Wang Y, Parker CE, Bhanji T, Feagan BG, MacDonald JK. Oral 5-aminosalicylic acid for induction of remission in ulcerative colitis. Cochrane Database Syst Rev 2016;4:CD000543. doi: 10.1002/14651858.CD000543.pub4.

8. Hanauer SB, Sandborn WJ, Kornbluth A, et al. Delayed-release oral mesalamine at $4.8 \mathrm{~g} /$ day (800 mg tablet) for the treatment of moderately active ulcerative colitis: the ASCEND II trial. Am J Gastroenterol 2005;100:2478-2485.

9. Lichtenstein GR, Kamm MA, Sandborn WJ, Lyne A, Joseph RE. MMX mesalazine for the induction of remission of mildto-moderately active ulcerative colitis: efficacy and tolerability in specific patient subpopulations. Aliment Pharmacol Ther 2008;27:1094-1102.

10. Sandborn WJ, Regula J, Feagan BG, et al. Delayed-release oral mesalamine $4.8 \mathrm{~g} /$ day (800-mg tablet) is effective for patients with moderately active ulcerative colitis. Gastroenterology 2009;137:1934-1943.e3. 